\title{
El Plan de Recuperación Financiera de las Haciendas de la Comunidad Autónoma de Canarias
}

Miguel Ángel Fernández Ballesteros *

\section{Introducción}

A finales de la década de los 80 la situación económica de los ayuntamientos canarios presentaba graves deterioros, cuyas causas se asocian a la crisis económica y a la caída del sector turístico que, junto con la implantación del nuevo sistema de financiación local, supuso una importante pérdida de ingresos para este conjunto de municipios. El deterioro de las haciendas municipales también estuvo ligado al importante esfuerzo inversor realizado de cara a las elecciones de 1991 y al déficit endémico de recursos que soportaban los municipios insulares para afrontar la ampliación de los servicios que prestaban.

Como resultado de lo anterior y de una deficiente gestión recaudatoria, se observaban importantes desajustes entre los compromisos de pago que se debían afrontar diariamente y los recursos disponibles para su financiación, deteriorándose progresivamente su capacidad para generar ahorro. Ante la insuficiencia de recursos propios y el agotamiento del recurso al crédito bancario, se produjo un notable descenso de la actividad inversora. La diferencia entre los ingresos presupuestados y los gastos ciertos comienza a neutralizarse renovando permanentemente las operaciones de tesorería y aplazando los pagos a proveedores, acumulándose ejercicio a ejercicio importantes déficits que a finales de 1992 absorbian el 26,8\% de los ingresos corrientes.

Esta situación motivó un encargo del gobierno de Canarias a ASERLOCAL con objeto de conocer con precisión la situación económica de los ayuntamientos canarios, y proponer las medidas necesarias para su recuperación económico financiera. Los principales desequilibrios encontrados en las haciendas municipales canarias a finales de 1992 , se resumen en los siguientes puntos:

- Drástica caída de la capacidad para generar ahorro hasta alcanzar tasas prácticamente nulas.

- Incapacidad para hacer frente a los gastos más perentorios.

- Insoportables tensiones de liquidez.

- Pérdida de la capacidad inversora.

- Agotamiento de las vías ortodoxas de financiación, sustitución del largo por el corto plazo.

- Carga financiera creciente.

- La recaudación tan sólo alcanzaba al 61,7\% de los derechos emitidos por ingresos tributarios.

- Las deudas a corto plazo suponían el 90\% de los ingresos corrientes.

Esta situación que, con matices, afectaba a la totalidad de los municipios de la región, impulsó al Gobierno de Canarias a poner en marcha un Plan de Saneamiento de las Haciendas Municipales y a crear un Fondo destinado a eliminar las graves tensiones de liquidez que soportaban la mayoría de los ayuntamientos del archipiélago. A través del tratamiento individualizado de los problemas de gestión económica de los ayuntamientos, la inyección de liquidez aportada por el Gobierno Canario y la reactivación de la economía, han permitido eliminar los problemas más acuciantes que soportaban las finanzas municipales. 


\section{Desarrollo técnico del programa}

\section{Objetivos}

El objetivo básico del Programa era la recuperación financiera de los ayuntamientos, definida de acuerdo con unos criterios de salud financiera, en un plazo de cuatro años.

Junto con este objetivo prioritario, se formularon una serie de principios que habían de inspirar las medidas a implantar para alcanzar el objetivo enunciado. Estos principios fueron:

- No discriminación. No se podía penalizar a ayuntamientos que se encontraban en buena situación económica que, en muchos casos, se había debido a una gestión más prudente del gasto y de la inversión. Debían tener acceso a los fondos de cooperación al igual que los ayuntamientos en mala situación.

- Auionomia municipal. En todo caso, la adhesión al Programa debía ser voluntaria por parte de los ayuntamientos y no impuesta desde la Administración autonómica.

- Corresponsabilidad. El esfuerzo que realizaba la Comunidad Autónoma al transferir recursos propios a los ayuntamientos debía estar acompanado por medidas municipales tendentes a la misma finalidad. La aceptación de la corresponsabilidad era condición indispensable para poder acceder al Programa.

- Control y Seguimiento Continuo del Programa. Dado el carácter plurianual del Programa, se debía establecer un sistema minucioso de seguimiento anual que garantizase el cumplimiento de los compromisos asumidos y la evaluación del grado de progreso del Programa.

- Tratamiento individualizado. Dada la disparidad de situaciones, resultaba clave para el éxito del Programa que a cada Ayuntamiento se le diseñara y gestionara la forma de alcanzar los criterios de salud financiera de acuerdo con su propia situación de partida y su capacidad en el tiempo para alcanzar los objetivos previstos.

- Contratación de una consultora externa especializada. Esto permitía crear en la práctica un organismo de gestión independiente, sin presiones políticas. Con esta medida, se aislaban los criterios y decisiones técnicas de las tensiones a que se podrían ver sometidas en caso de que se hubiera constituido un organismo público jerárquicamente dependiente del Ejecutivo autonó- mico. Además, se conseguía la sujeción a los plazos de ejecución de los trabajos al evitar rigideces de procedimiento, así como un importante ahorro del gasto. La consultora a la que se encargaron los trabajos fue ASERLOCAL.

\section{- Ratios de Salud Financiera.}

Tras una primera fase de diagnóstico de la situación global de los Ayuntamientos canarios realizada por Aserlocal que permitió, gracias a la utilización de una metodología homogénea, valorar adecuadamente la gravedad y alcance de la crisis financiera de las haciendas municipales canarias, se procedió a valorar los recursos adicionales que el Gobierno de Canarias debería inyectar en el sistema para que, en el período de cuatro años, se alcanzaran los objetivos de salud financiera pactados con la FECAM (Federación Canaria de Municipios). Éstos quedaron definidos de la siguiente forma: un Ayuntamiento está en situación saneada cuando cumple la totalidad de los siguientes ratios:

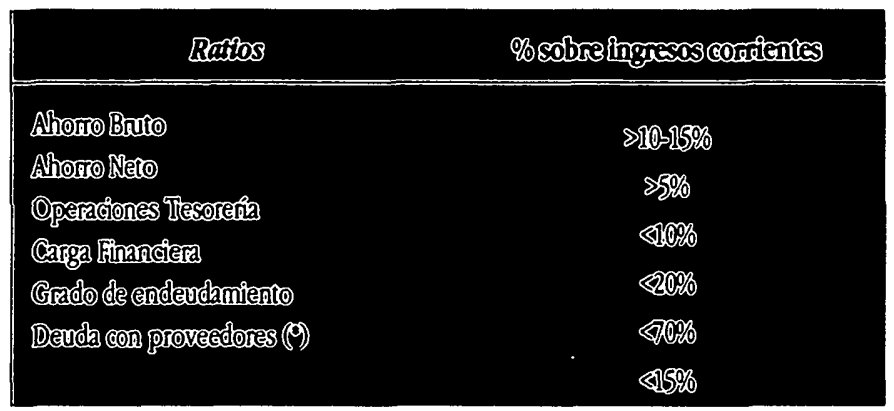

(`) Con antigüedad de devengo superior al año.

\section{Instrumentación del Programa}

La Comunidad Autónoma creó el Fondo de Saneamiento y Mejora de las Haciendas Municipales, dotándolo anualmente con 7.600 millones de pesetas. Estos recursos se distribuyeron anualmente entre los ayuntamientos que se adhirieron voluntariamente al programa de saneamiento. Como contraprestación a estas ayudas económicas, los ayuntamientos se comprometieron a adoptar una serie de medidas de ajuste de los gastos y cancelación de deudas acumuladas, instrumentándose en Planes de Actuación Individual. De esta forma, se ha dado un tratamiento personalizado a las especiales características que presentaba la situación económico-financiera de cada ayuntamiento, huyendo de soluciones igualitarias.

El instrumento jurídico bajo el que se desarrolló el Programa fue la Ley 3/1994, de Cooperación al Saneamiento y Mejora de las Haciendas Municipales Canarias. El Parlamento Canario promulgó esta Ley para regular los criterios para la distribución del 
Fondo, el acceso por los ayuntamientos al mismo, las obligaciones y compromisos de la Comunidad Autónoma y de los ayuntamientos y los mecanismos de sanción para los casos de incumplimiento.

\section{Definición del Programa}

ASERLOCAL definió una metodología específica para este Programa centrada en unas bases de planificación y en su ejecución por fases. Las bases que se propusieron fueron:

- Definir el Plan de Equilibrio Financiero como el conjunto de acciones y medidas dirigidas a mantener o restablecer los equilibrios básicos de los flujos económicos (ingresos y gastos) de una hacienda local.

- El Plan había de ser global y flexible. Global, ya que debe incluir todos los flujos de ingresos y gastos (corrientes, de capital y financieros). Y flexible, para introducir la posibilidad de corregir desviaciones y adaptarse a situaciones no previstas.

- La implantación de las medidas de racionalización económica incluidas en el Plan debían contemplarse en un borizonte temporal en el entorno de $3 / 4$ años, ya que la exigencia de continuidad de la actividad de la entidad local impide en múltiples ocasiones la regeneración del equilibrio económico en un plazo inferior.

- Era necesario dar un tratamiento diferenciado, atendiendo a la situación de partida de cada ayuntamiento, lo que obligaba de forma individual para cada ayuntamiento a diagnosticar la situación de partida, formular planes, controlar anualmente el cumplimiento de medidas y actualizar los planes anteriores. fases:

En cuanto a las fases para su ejecución, se distinguieron 4

\section{FASE: DLAGNÓSTICO ECONÓMICO-FINANCIERO PREVIO}

El objetivo de esta fase era detectar las causas que habían conducido a la situación deficitaria de la hacienda local y cuantificar la importancia de los problemas y desequilibrios más importantes que soportaban las haciendas municipales.

Para ello, fue necesario realizar un análisis pormenorizado de las principales magnitudes económicas y presupuestarias y especialmente de los siguientes aspectos:

a) Ingresos Corrientes: Estructura, nivel de presión fiscal, grado de dependencia de la hacienda local respecto a las transferencias procedentes de otras administraciones para la financiación de las operaciones corrientes, efica- cia recaudatoria referida a las distintas figuras tributarias, etc.

b) Gastos Corrienies: Estrucrura, crecimiento de los gasios de personal y de las compras de bienes y servicios, peso de las transferencias a organismos autónomos y empresas dependientes, grado de realización de las obligaciones comprometidas durante el ejercicio, análisis de la situación económica de los servicios municipales, generación de deudas de carácter extrapresupuestario.

c) Inversión: Volumen, estructura de financiación, grado de realización.

d) Aspectos Económico-Financieros:

- Aborro, entendido como la diferencia entre los ingresos y los gastos corrientes. Este indicador expresa la capacidad de la entidad para, una vez atendidos los gastos corrientes, invertir con cargo a recursos propios u obtener recursos para eliminar el déficit acumulado.

- Política de endelidamiento, saldo vivo pendiente de devolución, características de las operaciones suscritas, carga financiera,

- Delidas a corto plazo, recurso a la contratación de operaciones de tesorería, deuda acumulada con proveedores y Remanente de Tesorería (análisis de los derechos y obligaciones pendientes de cobro y pago, provisión por posibles insolvencias, etc.).

Asimismo, este proceso podía validarse estableciendo una comparación entre los principales ratios económico-financieros de la hacienda local analizada y los que se correspondian a una entidad local "saneada" ideal.

El siguiente paso estribaba en extraer las principales conclusiones del análisis para conocer de. forma precisa cuáles eran los problemas relevantes y las causas que los produjeron.

\section{$2^{a}$ FASE: ELABORACIÓN DE LOS PLANES INDIVIDUALES DE EQUILIBRIO 1992-1996}

Partiendo del conocimiento exhaustivo de los desequilibrios, el Plan de Equilibrio definia, en primer lugar, los objetivos que se pretendian alcanzar y que pueden clasificarse en:

\section{A.-Generales}

Mantenimiento/recuperación del equilibrio económico de las masas patrimoniales de carácter corriente.

- Recuperación de la solvencia frente a terceros.

- Absorción del déficit acumulado.

- Consecución de un determinado nivel de inversión. 


\section{B.-Instrumentales}

Se referenciaban a la consecución de los objetivos de salud financiera descritos anteriormente (por ejemplo, que el nivel de ahorro supere el $10 \%$ de los ingresos corrientes, disminuir el nivel de endeudamiento hasta que el saldo vivo por este tipo de operaciones no supere el $70 \%$ de los ingresos corrientes, etc.).

Para facilitar la consecución de los objetivos definidos, las líneas básicas de actuación podían ordenarse con arreglo a la sjguiente clasificación en función de las variables a las que afectaban:

- Medidas sobre limitación del crecimiento o reducción de los gastos corrientes.

- Medidas dirigidas a fortalecer la estructura de los ingresos corrientes y su recaudación.

- Medidas sobre control de las inversiones y del endeudamiento.

En cada caso había que seleccionar una opción lo más adecuada posible a la situación económica de la entidad local y evaluar sus posibilidades. Así, si por ejemplo el nivel de presión fiscal era bajo y la situación económica del municipio lo permitía, se ponía el acento en medidas de incremento de los ingresos a través de la utilización del recorrido fiscal. Si, por el contrario, el gasto corriente era elevado, las líneas de actuación incidian en el control y racionalización de éstos. Normalmente, las soluciones de ajuste exigían una combinación de todas ellas.

La cuantificación de las medidas a través de escenarios económicos permitiría medir el impacto derivado de su adopción en futuros ejercicios.

\section{3ㅁ FASE: IMPLANTACIÓN}

Los Planes de Equilibrio son "papel mojado" si no existe una voluntad y resolución firme de los gestores políticos y técnicos de implantar las medidas que comprenden. Su proceso de implantación únicamente es posible cuando existe un alto grado de compromiso de los responsables locales con los objetivos que se persiguen.

Para solventar este riesgo se consideró que la implantación del Plan de Equilibrio podía favorecerse con el diseño de un Programa de Implantación en el que, una vez definidos los distintos aproyectos" a abordar, se determinasen:

- Los objetivos a alcanzar con la puesta en marcha del proyecto.

- Las personas implicadas en su consecución.

- Las tareas y funciones a desempeñar por cada agente.
- La planificación temporal de consecución de objetivos con inclusión de objetivos intermedios.

- El calendario de reuniones de los comités de coordinación.

La definición de objetivos inmediatos y asequibles evitaba que se produjesen sensaciones de desaliento y desmoralización que se dan cuando se plantean tareas amplias, complejas y desproporcionadas a los medios disponibles. Para ello también resultaba útil la interposición de objetivos intermedios que permitiesen medir el progreso y corregir desviaciones.

\section{4ª FASE: CONTROL Y SEGUIMIENTO}

El proceso de evaluación y control era relevante para analizar:

- El grado de consecución de los objetivos establecidos para el ejercicio económico.

- Las desviaciones respecto a las previsiones iniciales y sus causas.

- Los nuevos desequilibrios que hubieran podido surgir a lo largo del ejercicio económico.

La fase de evaluación era esencial para determinar la nueva situación de partida, los avances obtenidos y el diferencial existente respecto a los objetivos finales planteados para el período, constituyendo la herramienta a través de la cual se retroalimentaba el sistema, ya que, a partir de los resultados obtenidos en cada ejercicio, se revisó y modificó el Plan de Equilibrio incorporando nuevos objetivos o adecuando los existentes.

La fase de evaluación se basaba en el análisis del grado de cumplimiento de las líneas básicas de actuación definidas para el ejercicio y en su incidencia sobre el comportamiento de los principales ratios de carácter económico-financiero (ahorro, carga financiera, endeudamiento, etc.). La evaluación también podía añadir la utilización de otros criterios de gestión relacionados con la eficacia y la eficiencia en la gestión, analizando su grado de acercamiento o alejamiento respecto al resultado obtenido por la media del sector.

\section{Aplicación}

Los trabajos se comenzaron en octubre de 1992. En diciembre de ese año el Gobierno Canario dispuso de una primera aproximación global del volumen de la deuda a corto y largo plazo que soportaba el conjunto de ayuntamientos canarios. A lo largo de 1993 se realizaron los Diagnósticos y los Planes de Equilibrio para cada uno de los 87 ayuntamientos de la Comunidad Autónoma que se adhirieron inicialmente al Plan. Entre 
1993 y 1996 se aplicaron las medidas propuestas, se revisó su cumplimiento y se actualizaron anualmente los Planes.

Los Planes de Actuación se han revisado anualmente con el fin de comprobar si las deficiencias de partida detectadas en la fase de diagnóstico estaban siendo corregidas a medida que avanzaba la implantación del programa de saneamiento y analizar el grado de cumplimiento de las medidas de racionalización económica previstas en los diferentes Planes de Actuación.

En el año 1998, de común acuerdo entre la Federación Canaria de Municipios y el Gobiemo autonómico, se decidió continuar con un nuevo Plan cuatrienal que permitiese profundizar en el saneamiento económico en los ayuntamientos que aún no habian alcanzado totalmente los criterios de salud financiera y no perder la posición en aquellos que ya se hallaban en esa situación.

\section{Resultados}

\section{Cuantitativos}

Atendiendo a la evolución de las principales variables económico-financieras de los ayuntamientos canarios a lo largo del período de aplicación del programa de saneamiento, puede afirmarse que la mayor parte de los problemas que afectaban a las haciendas municipales a finales de 1992 han desaparecido o se han mitigado.

\section{Recuperación de la capacidad para generar elevadas tasas de aborro}

El ahorro (definido como diferencia entre los ingresos y gastos corrientes) experimentó un crecimiento espectacular en el cuatrienio 1993/1996 debido al notable crecimiento de los ingresos (23\%) que ha permitido absorber el acumulado por los gastos $(17,8 \%$, paralelo a la inflación) y obtener recursos excedentarios para destinarlos a la financiación de las inversiones y a la rectucción del déficit acumulado. En relación con los ingresos corrientes, los porcentajes de ahorro neto han crecido significativamente pasando del 3,6\% de éstos en 1992 al 14\% en 1996. El incremento de los ingresos se debe a los siguientes factores:

\section{Desarrollo de la capacidad impositiva}

La presión fiscal ha experimentado un crecimiento del 18,6\% hasta alcanzar 42.768 pesetas/habitante en 1996, debido a la progresión del Impuesto sobre Bienes Inmuebles de Naturaleza Urbana que acusa los efectos de las numerosas revisiones catastrales que han entrado en vigor en varios municipios, provocando un aumento del $60 \%$ del valor catastral de la superficie urbana y del incremento de los tipos impositivos. Asimismo, las tasas y precios públicos obtenidos como contraprestación por el servicio de abastecimiento de agua y recogida de basuras también registran un notable incremento con el fin de paliar los déficit que se derivaban de su explotación.

\section{Ahorro bruto y neto 1993/1996}

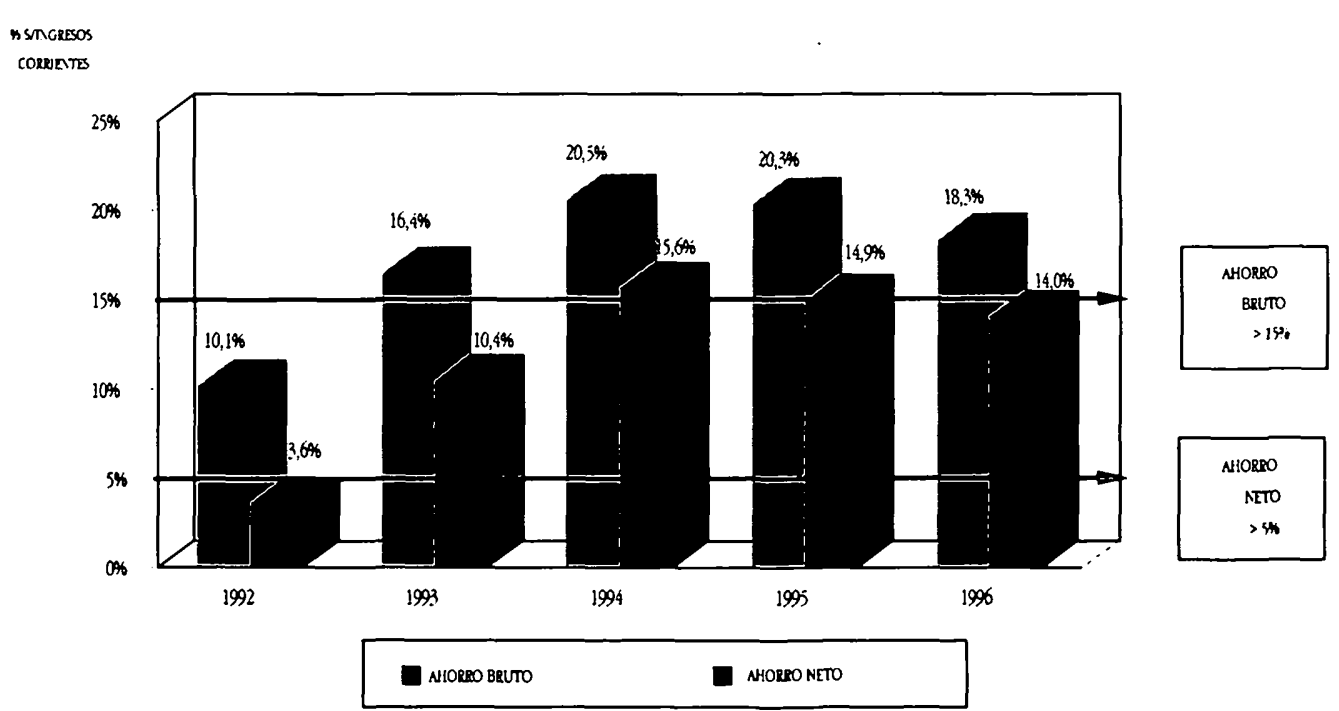




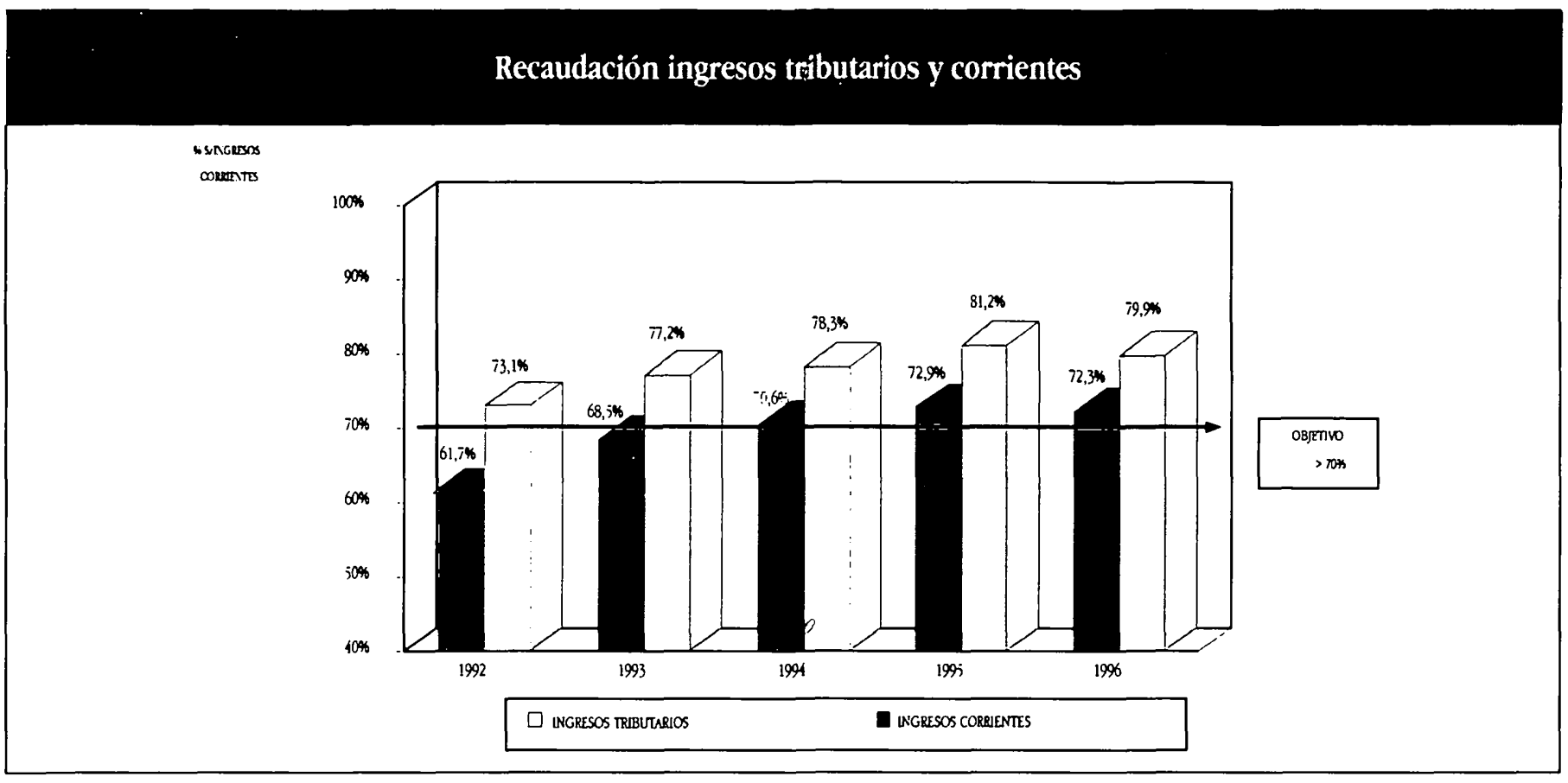

\section{Comportamiento expansivo de las transferencias corrientes}

La recuperación de la economía en general y el relanzamiento del turismo han favorecido el crecimiento de las transferencias derivadas de la participación de los municipios en el Régimen Económico Fiscal de Canarias y también debe señalarse el aumento de los recursos procedentes de la participación de los municipios en los ingresos del Estado, si bien el aumento de estos últimos también acusa los efectos del acuerdo suscrito para lograr la equiparación de los ayuntamientos canarios con los peninsulares en la consideración del factor población para la distribución de estos fondos.

El crecimiento de los ingresos ha venido acompañado de notables mejoras en su recaudación. Así, si en 1992 los ayuntamientos tan sólo recaudaron durante el ejercicio el $61 \%$ de los derechos emitidos por las diferentes figuras tributarias, durante el período 1993/1995 se observa un incremento anual de dos puntos hasta alcanzar en 1995 el 72,9\%, (72,3\% en 1996), si bien todavía se observa un amplio margen para alcanzar los resultados obtenidos por la media nacional de municipios en $1995(77,1 \%)$.

La reducción de la carga financiera contrarrestó el crecimiento de los gastos de funcionamiento.

Los gastos corrientes han aumentado moderadamente $(17,8 \%)$, aunque su evolución esté condicionada por la conjunción de los siguientes factores:
- Expansión de los gastos de personal, compras de bienes y servicios y transferencias corrientes en un 25,7\%. Las carencias en recursos humanos y materiales que presentaban los ayuntamientos han sido paliadas en gran medida durante este periodo explicando el excepcional crecimiento de los gastos de funcionamiento.

- Reducción de los gastos financieros. La carga financiera experimentó un descenso acumulado del 17\% en el período 1993/1996 debido al desarrollo por parte de los ayuntamientos de una política muy activa de refinanciaciones de los saldos adeudados a largo plazo, con el fin de beneficiarse de la reducción de los tipos de interés que ha caracterizado la evolución de los mercados financieros en los últimos años. Las operaciones de refinanciación han provocado un efecto adicional consistente en el diferimiento de las cargas financieras que se derivan de estos préstamos a ejercicios futuros, ya que habitualmente se pactaron con períodos de carencia de pago de amortizaciones que trascienden del ejercicio 1996.
Restablecimiento de la liquidez y de la capacidad de pago

El aumento de los ingresos corrientes y los avances en su recaudación han permitido a las haciendas locales afrontar un elevado volumen de obligaciones devengadas en el período y reducir las deudas acumuladas a corto plazo con proveedores y 


\section{Carga financiera 1993/1996}

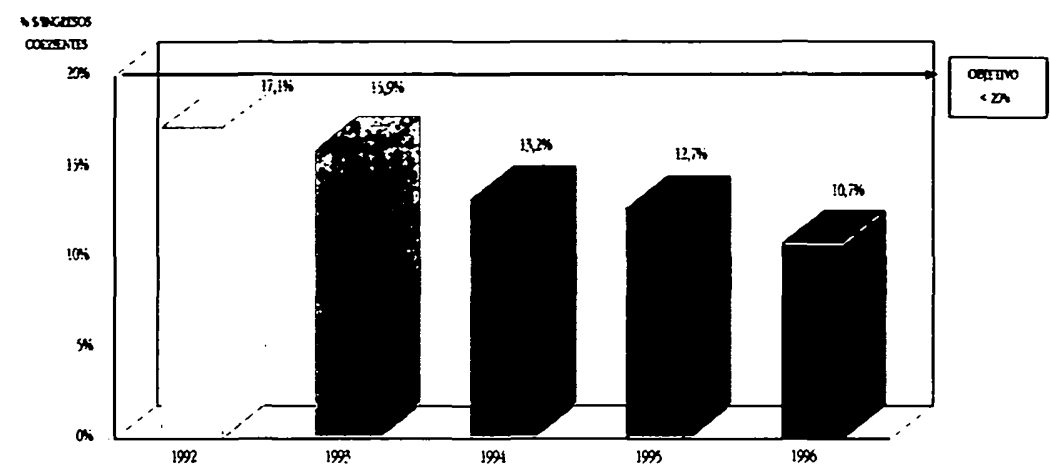

entidades financieras en un $13,2 \%$ hasta situarse a finales de 1996 en 79.210 millones de pesetas (91.301 millones en 1993).

De cada cuatro pesetas que los ayuntamientos han destinado a cancelar deudas a corto plazo acumuladas a 31/12/1992, y las que iban quedando pendientes al final de cada ejercicio, 1 peseta procede del Fondo de Cooperación al Saneamiento.

El sistema de financiación de las haciendas locales se ha nutrido de ingresos estables que, además, se cobran realmente, lo que ha permitido reducir las tensiones de liquidez acumuladas en los ejercicios precedentes provocadas por la presupuestación de ingresos ficticios.

La recuperación de la capacidad de pago también es evidente si se considera el creciente porcentaje de obligaciones generadas en cada ejercicio que los ayuntamientos han logrado satisfacer. Mientras que en 1992 los ayuntamientos pagaron 72,1 pesetas de cada 100 pesetas gastadas durante el mismo, en 1996 se lograron cancelar 79,1 pesetas.

\section{Endeudamiento financiero a largo plazo 1993/1996}

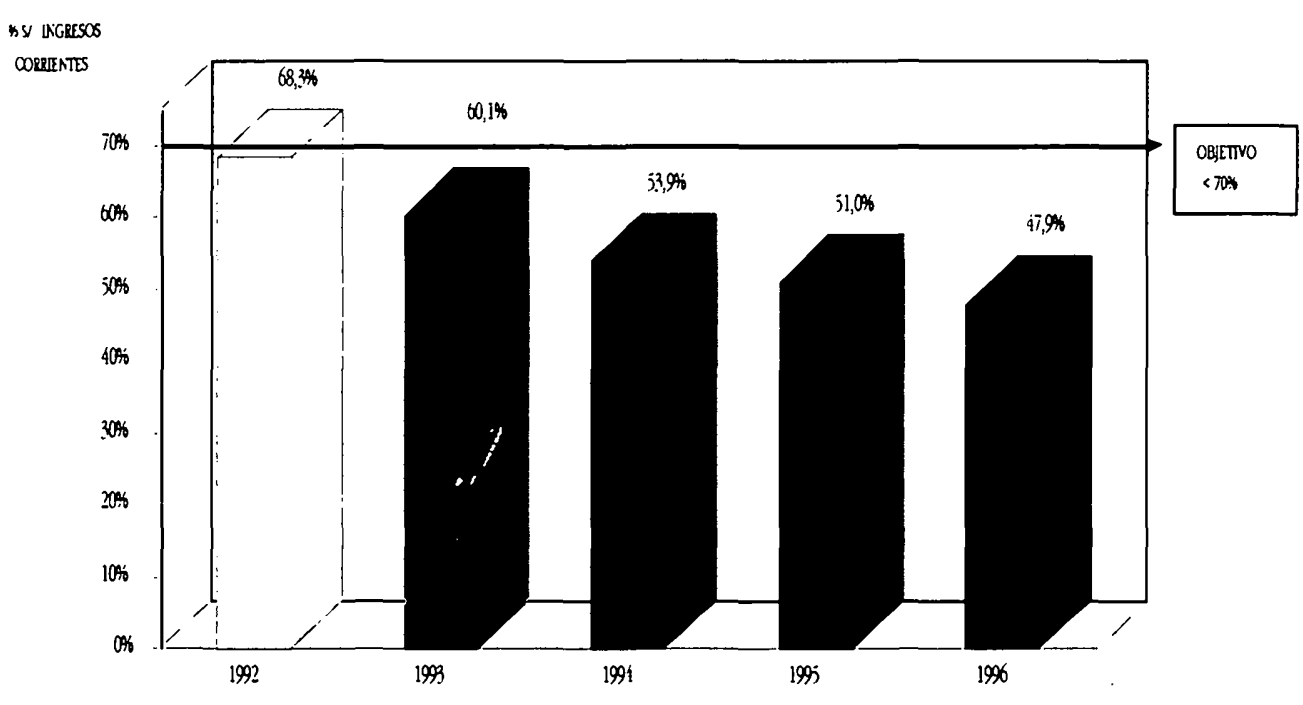




\section{Operaciones de tesoreria 1993/1996}

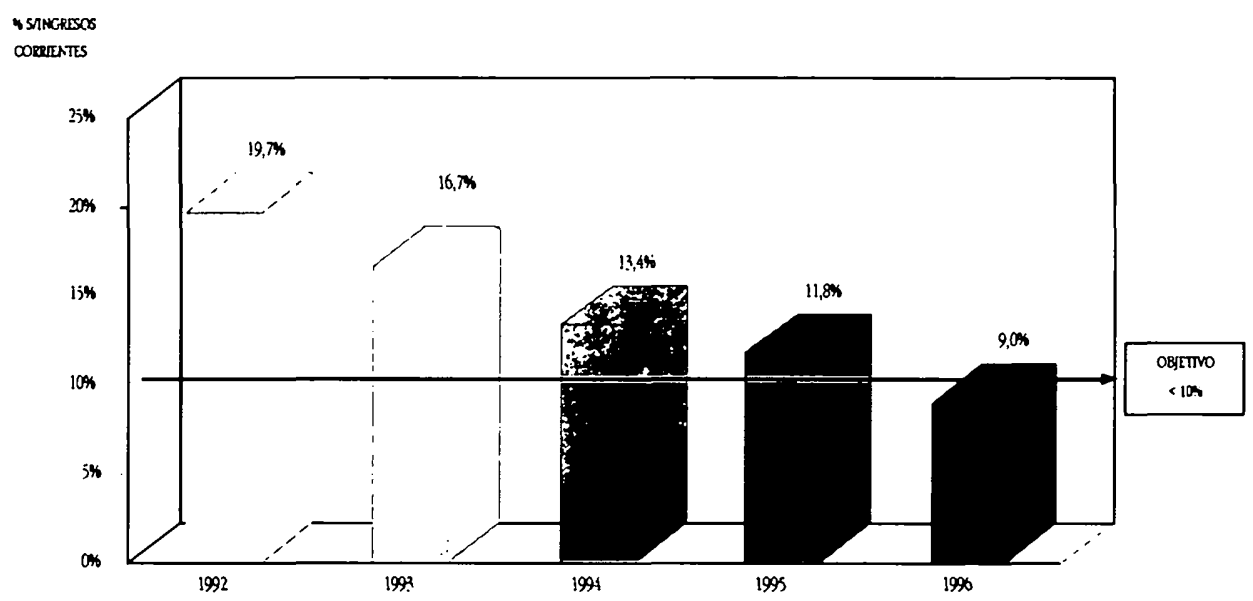

D)eroge

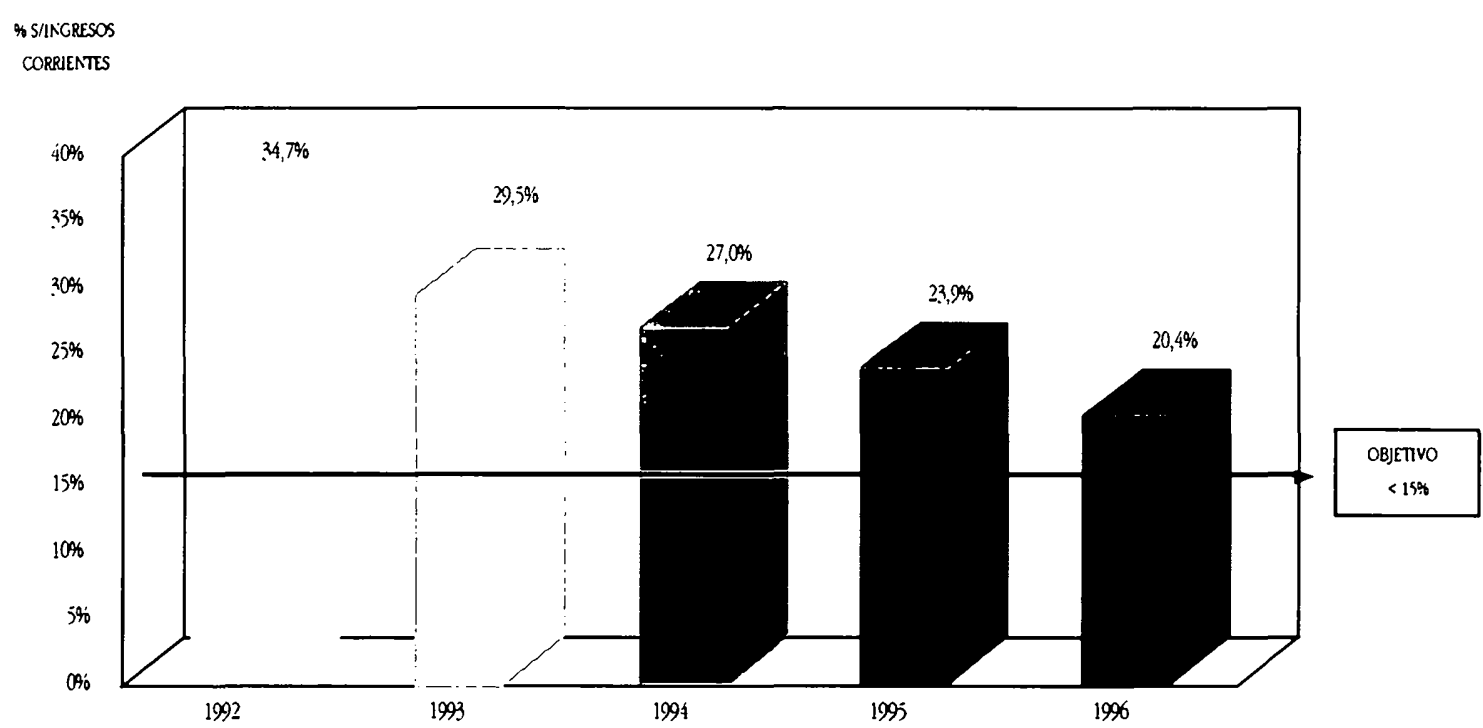

Relanzamiento controlado de la inversión, frenándose el recurso al crédito bancario

Los ayuntamientos han mantenido una política de inversión moderada en consonancia con el proceso de saneamiento económico de estas entidades, destinando a este fin el 19,6\% de los gastos comprometidos en el período. La liquidez obtenida en el desarrollo de las operaciones diarias (ahorro) hizo menos necesario el recurso a la contratación de nuevo endeudamiento financiero a largo plazo para garantizar su cobertura financiera, manteniéndose las transferencias de capital procedentes de otras administraciones como principal fuente de financiación de las inversiones.

El prudente comportamiento de los ayuntamientos respecto a las nuevas contrataciones de endeudamiento ha permitido minorar el peso de estas operaciones sobre la economía municipal, pasando a representar su saldo pendiente de devolución el 48\% de los ingresos corrientes en 1996 (mientras que en 1992 se elevaba al $68,3 \%)$. 
El déficit acumulado registra un sensible descenso, basta representar el $15 \%$ de los ingresos corrientes

El déficit, medido como diferencia entre el saldo de deudores y acreedores a corto plazo, experimentó una positiva evolución durante la aplicación del Plan de Saneamiento, disminuyendo hasta 18.857 millones de pesetas en 1996. (21.631 millones en 1993, $21,4 \%$ de los ingresos corrientes).
La inyección de liquidez que han proporcionado los crecientes ingresos corrientes recaudados ha permitido compatibilizar la reducción de las deudas acumuladas a corto plazo con entidades financieras (operaciones de tesorería) y proveedores, con la cancelación de importantes volúmenes de obligaciones contraídas durante los respectivos ejercicios de aplicación del Plan.

\section{Deerpors 1993/1906}

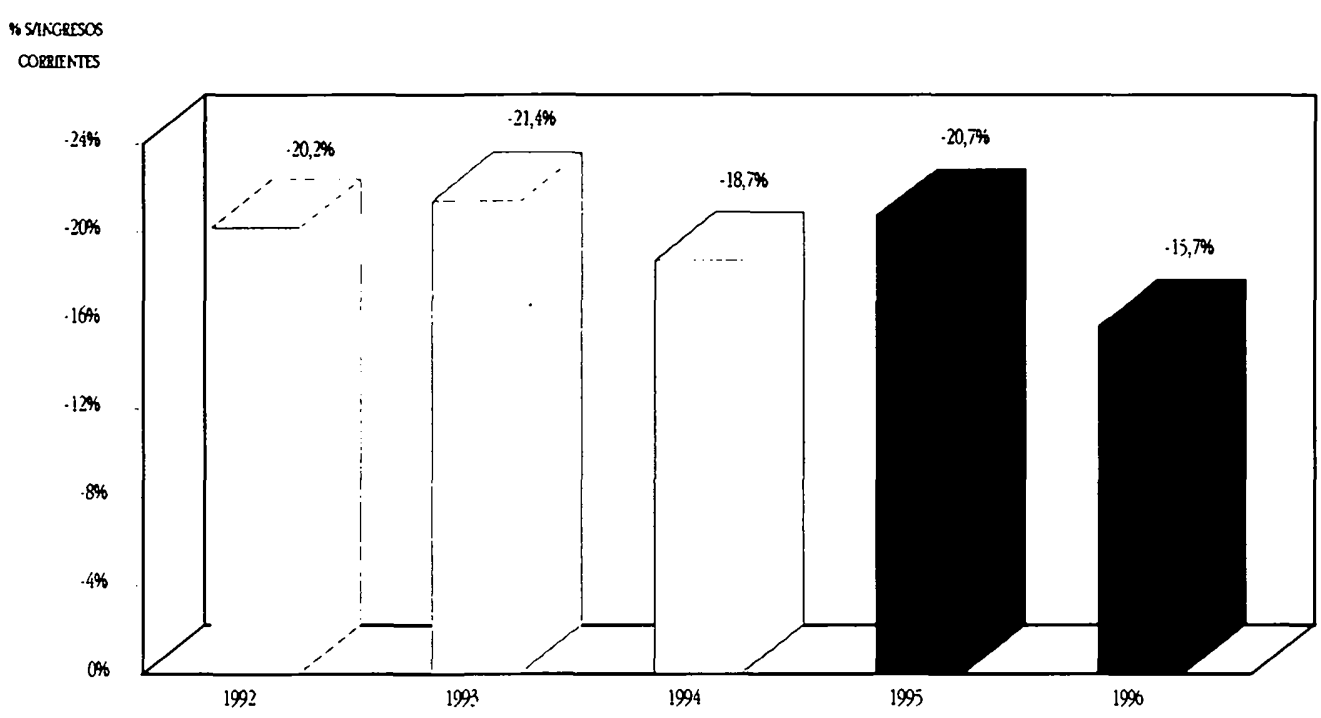

- Los ayuntamientos ban logrado alcanzar todos los objetivos de salud financiera, a excepción del referente a deudas con proveedores con antigüedad de devengo superior al año

La favorable evolución de las finanzas municipales en el cuatrienio 1993/1996 se sintetiza en la consecución de los objetivos establecidos para el conjunto de ratios que inciden sobre las principales variables económicas y presupuestarias de las haciendas locales (en términos relativos a los ingresos corrientes) que han actuado como "marco de convergencia" de las haciendas municipales. En términos agregados se han logrado alcanzar todos los objetivos de salud financiera", a excepción de la magnitud que mide la importancia de las deudas con proveedores que, no obstante, también ha experimentado una evolución muy positiva, presentando una desviación de tan sólo cuatro puntos respecto al objetivo propuesto.

\section{Cualitativos}

Además de las mejoras de carácter cuantitativo señaladas en los anteriores párrafos, el Plan de Saneamiento también ha impulsado la adopción de medidas cualitativas que han favorecido una gestión económico-financiera más eficaz y la resolución de algunas de las deficiencias que soportaban los ayuntamientos a finales de 1992.

\section{Planificación presupuestaria con proyección plurianual}

Los ayuntamientos se han acostumbrado a planificar su actividad en el medio plazo al contar con un documento (Plan de Actuación) que trasciende del año natural, en el que se anticipan los problemas que puede provocar la adopción de una determinada decisión en el futuro, dando las pautas para su resolución. 


\section{Evolución de la situación económico-financiera (1992/1996)}

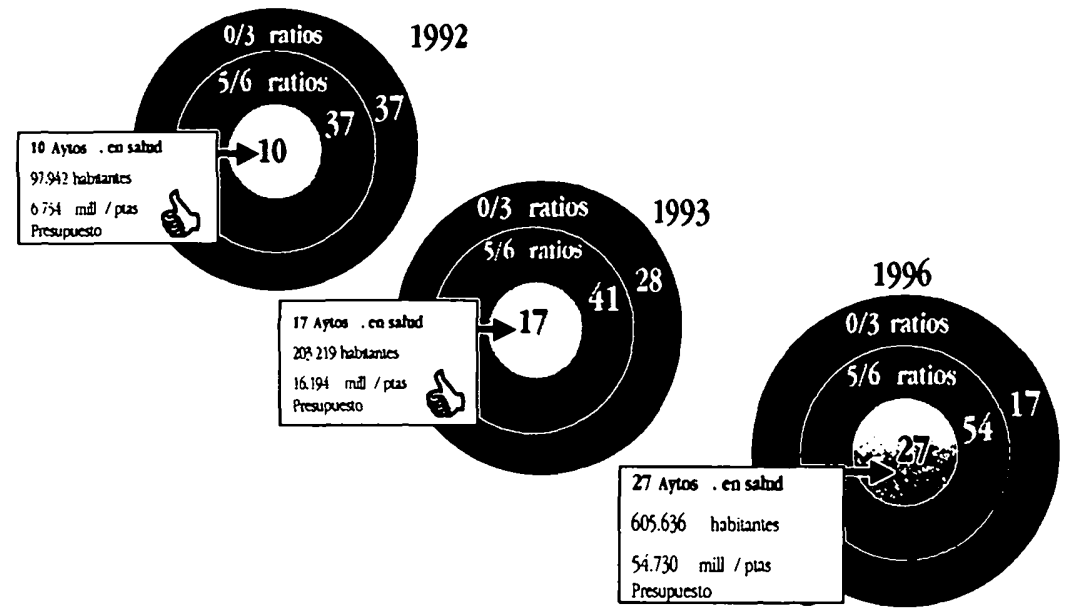

Presupuestación de los ingresos más ajustada a la realidad

La práctica de presupuestar ingresos ficticios para dar cobertura a gastos ciertos se ha abandonado paulatinamente, por lo que la cobertura de los gastos se apoya en ingresos reales y estables.

\section{Gestión recaudatoria más eficaz}

La mejoría de la recaudación no es ajena a los trabajos de inspección fiscal y depuración de padrones recomendados en los Planes de Actuación y desarrollados por un buen número de ayuntamientos, lo que se ha visto acompañado de la adecuación del calendario fiscal al año natural con el fin de recaudar el mayor volumen de derechos dentro del ejercicio en el que se devengan.

Formalización de convenios con entidades financieras para facilitar el pago de deudas a proveedores

Con el fin de disminuir el período medio de pago a los proveedores, los ayuntamientos han suscrito acuerdos con entidades financieras que han adelantado recursos para destinarlos a la cancelación de las deudas a corto plazo.
Recuperación de la finalidad original de las operaciones de tesoreria

A finales del ejercicio 1992, la gravedad de las tensiones de liquidez impedía hacer frente a la devolución de estas operaciones renovándose año tras año. El restablecimiento de la liquidez ha hecho menos necesaria la utilización de estas operaciones, reduciéndose progresivamente su saldo y recuperando su finalidad original de paliar desfases transitorios de liquidez.

\section{Desarrollo de la colaboración intermunicipal}

En el período de aplicación del Plan se ha desarrollado el asociacionismo municipal, creándose mancomunidades y entidades supramunicipales con el fin de reducir los costes de prestación de los servicios y reunir un conjunto de población suficiente para solicitar subvenciones a la Unión Europea.

De los anteriores párrafos puede deducirse que la situación de estrangulamiento económico de los ayuntamientos a finales de 1992 se ha superado con la aplicación del Plan de Saneamiento y Mejora, ya que el crecimiento moderado de los gastos junto con la expansión de los ingresos ordinarios, acompañado de mejoras en su recaudación, han permitido recuperar la capacidad de los ayuntamientos para generar elevados niveles de ahorro reales e inyectar liquidez al sistema de financiación de las haciendas municipales. La recuperación de la liquidez ha 
posibilitado que las operaciones de tesorería vuelvan a adquirir su fin original de cubrir desfases temporales entre cobros y pagos, reduciéndose su saddo paulatinamente. Las anteriores circunstancias y la asunción de un nivel moderado de inversión, en consonancia con los objetivos de saneamiento económico, también ha incidido positivamente en la recuperación de la solvencia y capacidad de pago de estas entidades, lográndose reducir considerablemente el volumen de las deudas adquiridas a corto plazo con proveedores.

Por último, la positiva evolución de los mercados financieros y el desarrollo de una política activa de refinanciaciones de los saldos suscritos por endeudamiento a largo plazo, han proporcionado un balón de oxígeno temporal, al minorarse la cuantía de los gastos financieros y diferirse el pago de las amortizaciones a futuros ejercicios.

\section{Factores de éxito}

En el éxito que ha supuesto el Plan de Recuperación Financiera de las Haciendas Municipales han intervenido, entre otros, los siguientes factores básicos:

- Una voluntad decidida de todas las fuerzas políticas presentes en la Comunidad Autónoma para abordar el problema de la autonomía financiera municipal y apoyar su resolución. A este respecto cabe destacar que, durante el proceso, se han producido altemancia de partido y de responsables públicos en el Ejecutivo autonómico, sin que estos cambios hayan afectado en ningún momento al desarrollo del Plan.

- Consenso entre dichas fuerzas y entre los responsables del Gobierno autonómico y los representantes municipales presentes en la Federación Canaria de Municipios, lo que ha permitido ir superando las dificultades y discrepancias que iban surgiendo en un programa tan complejo.

- La inyección de liquidez proveniente del Fondo ha tenido, gracias a la aplicación rigurosa de los objetivos personalizados en cada plan, un efecto multiplicador sobre su situación económica y también sobre la de su entorno (proveedores, elc.).

- Respeto al trabajo de asistencia técnica realizado por ASERLOCAL, deslindando claramente las componentes políticas y técnicas de las decisiones.

- Voluntad y autodisciplina de los responsables municipales para aplicar las medidas propuestas.

- Implantación progresiva y volıntaria de una nueva cultura de gestión pública y de adaptación de técnicas y metodología de planificación al ámbito público.

\section{Conclusiones}

El éxito del proceso estriba en la combinación de medidas técnicas y políticas, un tratamiento individualizado y justo* para cada situación y una inyección económica suficiente para alcanzar los objetivos previstos.

El saneamiento de las entidades locales canarias ha tenido una enorme incidencia en la economía del archipiélago, aliviando tensiones con proveedores y posibilitando un desarrollo de la inversión pública dentro de un marco de solvencia financiera.

La situación de equilibrio financiero ha permitido a los ayuntamientos canarios el plantearse objetivos más ambiciosos, ligados a la mejora de los servicios y a un desarrollo territorial equilibrado.

La introducción en los ayuntamientos de técnicas de gestión basadas en la planificación a medio plazo hace difícil pensar que se pudieran volver a reproducir situaciones como las de 1992.

El conocimiento y difusión de la situación económico-financiera de los ayuntamientos canarios tanto por parte del gobierno como de la sociedad canaria es hoy la mejor base para una gestión madura y responsable del pacto local.

- Director General de ASERLOCAL. 
